\title{
A JUSTIÇA GERAL EM TOMÁS DE AQUINO
}

Carlos Artur R. do Nascimento*

SÍNTESE - O presente trabalho visa apresentar a noção de justiça geral de acordo com Tomás de Aquino, bem como a evolução desta noção desde o Comentários às sentenças até a Suma de Teologia.
ABSTRACT - This work intends to present the notion of general justice according to Thomas Aquinas, as well as the evolution of this notion from the Commentary to the Sentences till the Summa of Theology.

Na Suma de Teologia (II, II, qu. 58), ao tratar da justiça, T. de Aquino pergunta no a. 6 "se a justiça, na medida em que é geral, é o mesmo em essência com toda virtude". Sua reposta é perfeitamente clara e se baseia na distinção de uma dupla maneira de algo ser denominado geral. Dupla maneira, aliás já estabelecida na I II, qu. 46, a. 1. Com efeito, algo pode ser dito geral por predicação, assim como animal é geral em relação ao homem, ao cavalo e às outras espécies de animais. Neste caso o geral é essencialmente o mesmo que aquilo em relação ao qual é geral, pois o gênero faz parte da essência da espécie e entra na definição desta. Mas, algo pode também ser dito geral pela sua causalidade ou influência; assim, o Sol é dito ser a causa geral em relação a todos os corpos que são iluminados ou transformados por sua atividade. Aqui não é necessário que o geral seja o mesmo em essência com aquilo em relação ao qual é dito geral, pois a essência da causa não é a mesma que a do efeito.

É desta segunda maneira que a justiça pode ser dita uma virtude geral. Quer dizer: na medida em que, tendo por objeto o bem comum, ordena a este os atos das outras virtudes.

Como cabe à lei ordenar para o bem comum (Cf. I II, qu. 90, a. 2), tal justiça é denominada justiça legal porque, por meio dela, o ser humano se harmoniza com a lei que ordena os atos de todas as virtudes para o bem comum. Deste modo, a justiça legal é em sua essência uma virtude particular cujo objeto próprio é o bem comum. Move, no entanto, por comando, todas as outras virtudes, sendo, nesta medida, chamada de geral.

Segue-se, então, que tal virtude se encontra principalmente e de modo como que arquitetônico no príncipe; encontrando-se de modo secundário e ministrativo nos súditos.

\footnotetext{
Universidade Estadual de Campinas - UNICAMP
} 
Tal é a exposição do corpo do artigo 6, tendo em conta os elementos do artigo 5. É ela já apresentada a modo de alusão em duas passagens da I II: qu. 60, a. 3, ad $2 \mathrm{~m}$ e qu. 61 , a. 5 , ad $4 \mathrm{~m}$.

Tomás de Aquino termina sua exposição com a seguinte observação:

"No entanto, qualquer virtude, na medida em que é ordenada ao bem comum pela supracitada virtude, particular quanto à essência e geral pela influência, pode ser denominada justiça geral. De acordo com este modo de falar, a justiça legal é o mesmo em essência com toda virtude e difere quanto à noção. É deste modo que o Filósofo fala" (Ética a Nicômaco, V. 1130 a 12).

É sempre aconselhável desconfiar de declarações deste teor. Como E. Gilson ${ }^{1}$ relembra várias vezes, Tomás de Aquino reinterpreta seus predecessores (inclusive Aristóteles) à luz de seus próprios princípios, dando a impressão de que se equivoca constantemente sobre a doutrina destes. Pura ilusão, pois o resultado é constante: Tomás está sempre fazendo seus predecessores dizerem o que ele próprio pretende dizer. Aqui no caso estaria ele encobrindo uma diferença, não só em relação a Aristóteles mas também em relação a seu primeiro ensino no Comentário às sentenças e nas Questões disputadas sobre a verdade.

De fato, no Scriptum super libros sententiarum (Livro III, Distinção IX, qu. I, a. I sol. II) Tomás de Aquino recorria a uma distinção de quatro membros (portanto, bem mais complexa que a da Suma de teologia que só comporta dois ${ }^{2}$ para situar em que sentido se pode falar de virtude geral. Lemos ai então:

"De um primeiro modo, porque é predicado de qualquer virtude, como a justiça legal que se converte com a virtude e é o mesmo quanto ao sujeito, diferindo quanto à noção, como diz o Filósofo no livro V da Ética (1130 a 9-14); é, assim, dita geral quanto à sua essência [...]. Portanto, a primeira generalidade é como que do universal".

Ainda no mesmo Scriptum super libros sententiarum (Livro III, Distinção XXXIII, qu. I, a. I, sol. III, ad 3m) encontramos uma explicação que não é perfeitamente clara e reproduz em parte o que foi dito na. distinção IX:

1 Ver, por exemplo, GILSON, E. A experiência na filosofia de S. Tomás. S. Paulo: Duas cidades, 1962, p. 12.

2 Utilizamos a edição da Summa Theologiae. Roma: Paulinas, 1962; do Scriptum super Libros Sententiarum. Paris: Lethielleux, 1956; das Quaestiones Disputatae. Turim: Marietti, 1953, 10v. Nos auxiliaram também:

COUSNONGLE, V. "De la notion de vertu générale chez Saint Thomas d'Aquin". Revue des Sciences Philosophiques et Théologiques, Paris: v. 43, p. 601-620, 1959;

GAUTHIER, R. A. Magnanimité, l'idéal de la grandeur dans la philosophie païenne et dans la théologie chrétienne. Paris: Vrin, 1951, p. 360-371;

OLIVEIRA, C.J.P. "Nota sobre a justiça 'geral' de S. Tomás e a modema 'justiça social"w, Mimeografado.

Podemos resumir da seguinte maneira os quatro modos de uma virtude ser geral, indicados na distinção IX do comentário ao livro III das Sentenças;

1) por predicação das demais virtudes = generalidade do universal - exemplo = justiça legal;

2) por dependência, por receberem participação de seu ato = generalidade da causa que dá o ser exemplo = prudência;

3) por operar acerca dos atos de todas as virtudes = generalidade do que move por comando exemplo = magnanimidade;

4) por requerer os atos de diversas virtudes para seu ato $=$ generalidade do todo integral - exemplo $=$ magnanimidade. 
Uma certa justiça é geral e outra particular. Com efeito, é particular na medida em que tem uma matéria determinada: os relacionamentos que dizem respeito a outrem sob o aspecto de débito; é deste modo que é posta aqui como uma das quatro virtudes cardeais.

É dita geral de outro modo, e isto duplamente. De um modo, na medida em que é uma certa postura reta da própria alma, na medida em que o ser humano se ordena do modo devido, tanto em si mesmo como em relação ao resto; é assim que se diz que o ímpio é justificado. De outro modo, na medida em que é o mesmo que toda virtude, diferindo quanto à noção, na medida em que alguém ordena $o$ ato de virtude ao bem comum, de acordo com $o$ mandamento da lei; o que acontece nos atos de todas as virtudes como o Filósofo diz no livro V da Ética (1129 b 12 ss.) e isto será melhor esclarecido em seguida".

Afirma-se que a justiça pode ser dita geral de duas maneiras. A primeira destas se aparenta, pelo menos, à generalidade que lhe era atribuída na distinção $\mathrm{IX}$, isto é, a generalidade por atribuição (universalidade). A segunda parece remeter ao terceiro modo de generalidade da distinção IX: generalidade "na medida em que opera acerca dos atos de todas as virtudes de tal modo que todas lhe dizem respeito quanto à matéria" ou em outros termos, generalidade "do que move por meio do comando", o que nos aproxima já da solução apresentada mais tarde na Suma de Teologia.

Os esclarecimentos posteriores aparecem, por exemplo, na qu. II, a. I, sol. I, ad $1 \mathrm{~m}$, onde se diz que as virtudes cardeais "não são ditas gerais por predicação, mas por uma certa participação, como foi dito. Donde, não se thes imputar espécies e sim partes". Trata-se do segundo modo apresentado na distinção IX: "na medida em que dela dependem as outras virtudes que participam de seu ato". O exemplo dado era o da prudência, "pois, a partir dela, todas as outras virtudes morais participam da retidão da escolha $e$, deste modo, seu ato faz parte dos atos de todas as outras virtudes". Trata-se da generalidade "como que da causa doadora do ser".

Algo é acrescentado na qu. II, a. I, sol. III, ad $2 \mathrm{~m}$. Aí se distingue entre a generalidade da justiça e da prudência, por um lado, e, por outro, a da temperança e da força. As duas primeiras "são ditas gerais a respeito de todas as virtudes", ao passo que as duas últimas "apenas a respeito das virtudes que lhes são anexas". Esta última generalidade basta para caracterizar uma virtude cardeal, não se requerendo a primeira. Pode-se dizer que nada de substancial foi acrescentado. Tomás de Aquino limita-se a descartar certas dificuldades fazendo uso do quadro estabelecido previamente na distinção $\mathrm{IX}$.

A qu. III da distinção XX XIII apresenta logo no a. I, sol. I a importante distinção dos tipos de todo em três - universal, integral e potencial. ${ }^{3}$ Esta classificação não deixa de ter relação com os modos de generalidade. O primeiro tipo de todo, por exemplo, coincide com o primeiro modo de generalidade, tanto das Sentenças como da Suma; o segundo pode ser aproximado do quarto das Sentenças e o terceiro, do segundo modo de generalidade das Sentenças. No entanto, estas relações não são explicitadas ou analisadas.

3 Esta distinção que provém remotamente de Aristóteles e, mais imediatamente, de Alberto Magno, vai ser de grande importância para a organização das "partes das virtudes na II II. Cf. LOTTIN, 0. "Les vertus cardinales et leurs ramifications chez les théologiens de 1230-1250". In: Psycologie et morale aux XI" et XII' siècles. Louvain: Abbaye du Mont César: Gembloux: J. Duculot, 1949, Tome III. Seconde partie, I, p. 191-192. 
O quadro já conhecido da distinção XXXIII, qu. I, a. I, sol. III, ad 3m, é retomado no De veritate (qu. 28, a. 1, Respondeo 30, Alio modo). De fato, aí se fala da justiça como virtude particular, distinta das outras cardeais; da justiça legal que "de acordo com o Filósofo (Livro V da Ética, cap. 1) é toda virtude, diferindo da virtude apenas quanto à noção"; da justiça como "um certo estado próprio, de acordo com o qual o ser humano se posta na ordem devida em relação a Deus, em relação ao próximo e a si mesmo, de tal modo que nele as forças inferiores se subordinam à superior". Note-se a propósito do segundo membro (a justiça legal que se identifica com toda virtude) que a explicação é idêntica à já vista também na distinção XXXIII, isto é, "na medida em que alguém ordena o ato de virtude ao bem comum".

Comparando-se estas passagens do Comentário às sentenças e do De veritate com o artigo da Suma apresentado de início, é possivel perceber o caminho percorrido desde a complicação das Sentenças até a simplicidade e clareza da II II. Primeiro, Tomás de Aquino se livrou do emaranhado de distinções das Sentenças e depois se fixou sem hesitação na generalidade por influência da justiça legal. É claro que com isso se distanciou tanto da letra de Aristóteles como da tradição teológica anterior à tradução do livro $\mathrm{V}$ da Ética a Nicômaco para o Latim. ${ }^{4}$ Com efeito, ambos refletiriam um fundo religioso em que justiça quer dizer esta retidão para com Deus (ou os deuses), o próximo e consigo mesmo. É neste sentido que se fala, em termos cristãos, de justificação do pecador; para Aristóteles tal justiça seria coextensiva com a lei.

O mais importante encobrimento, no entanto, praticado por Tomás de Aquino é que ele atribui ao Filósofo sua própria doutrina acerca da justiça legal ou geral. Poderíamos esquematizar o pensamento de Aristóteles no livro V da Ética a Nicômaco da seguinte maneira:

\begin{tabular}{l|l|l} 
Justiça & Geral - idêntica ao conjunto das virtudes \\
Particular & Distributiva \\
Comutativa
\end{tabular}

Ora, este esquema é (ocultamente) transformado por Tomás de Aquino no seguinte:

Geral - idêntica ao conjunto das virtudes - toda virtude é uma forma de justeza ou retidão

\begin{tabular}{|c|c|c|c|}
\hline \multirow{3}{*}{ Justiça } & \multicolumn{3}{|c|}{$\begin{array}{l}\text { Geral - idêntica ao conjunto das virtudes - toda virtude é uma forma } \\
\text { de justeza ou retidão }\end{array}$} \\
\hline & & $\begin{array}{l}\text { Geral (legal) - ordenação do homen } \\
\text { ao bem comum; }\end{array}$ & tamente \\
\hline & & $\begin{array}{l}\text { Particular (cardeal) - ordenação do } \\
\text { homem imediatamente a bens } \\
\text { particulares }\end{array}$ & $\begin{array}{l}\text { Distributiva } \\
\text { Comutativa }\end{array}$ \\
\hline
\end{tabular}

4 Cf. LOTTIN, O. "Le concept de justice au moyen âge avant l'introduction d'Aristote". In: Ibidem, p. 283-299. 
Na reaildade Tomás de Aquino identifica uma forma estrita de justiça (pois há aí alteridade e débito rigoroso) que tem por objeto o bem comum da coletividade $\mathrm{e}$ pode mobilizar em vista deste qualquer virtude que se ocupa de um bem que é parte deste bem comum. Esta caracterização da justiça geral ou legal permite que ela seja relacionada coerentemente com a lei ("ordenação da razão em vista do bem comum") e com as funções da autoridade e dos membros da coletividade.

Verifica-se; pois, o acerto da advertência de Gilson mencionada mais acima. Confiar pura e simplesmente nas citações de "autoridades" pelos medievais pode ser perfeitamente enganador. É sempre bom ir verificar se é mesmo "deste modo que o Filósofo fala", ou Agostinho, ou Avicena, etc.. A retórica medieval está neste ponto no exato contrapasso dos tempos modernos. Assim como Galileu ou Descartes gostam de começar acentuando o novo, ainda que na linha seguinte se dediquem a repetir (ou até mesmo a copiar literalmente) algo não tão novo, Tomás de Aquino ou Duns Scot produzem muitas vezes alterações inéditas com todo o ar de não estarem mudando nada. Aliás, ninguém era bobo. Todo mundo sabia que a "autoridade tem um nariz de cera" e o próprio Tomás, tão discreto nessas coisas, não se priva de introduzir a inocente (e nada inocente) cláusula: "contanto que corretamente entendido". ${ }^{5}$

Um outro aspecto para o qual talvez valha a pena finalmente chamar atenção é indicado por Chenu e tem aqui uma aplicação típica já que, das Sentenças à Suma de Teologia, Tomás de Aquino constrói seu pensamento com base na distinção dos sentidos do adjetivo "geral":

"Resta que, explorada a este ponto pela arte de pensar, a arte de distinguir revela uma filosofia, ou melhor, uma mentalidade filosófica determinada" ${ }^{6}$

Ainda nos termos de Chenu, "lógica da determinação e da identidade", a de Tomás de Aquino e de João Duns Scot mais ainda, prolonga antes Aristóteles que Agostinho "para benefício de um pensamento decantado e de qualidade científica, mas em detrimento desta aura espiritual e até literária, que dilatava a significação imediata dos textos de tipo agostiniano".

5 Cf. Suma de Teologia II I, qu. 58, a. 1. Permito-me remeter ao texto de minha autoria "A serva da Teologia e a dama dos salões". In: Humanidades 8 (1992), Brasília: Edunb, p. 282-283.

6 CHENU, M.D. Introduction à l'étude de $S$. Thomas d'Aquin. Montréal: Institut d'Études Médiévales: Paris: Vrin, 1950, p. 147. 